\title{
Perancangan Sistem Pengepakan Otomatis Berbasis Arduino UNO Menggunakan Sensor Jarak Infra Red
}

\author{
Muh. Syarief Hidayat ${ }^{1)}$, Luther Pagiling ${ }^{2)}$, Muh. Nadzirin Anshari Nur ${ }^{3)}$ \\ ${ }^{1,2,3}$ Jurusan Teknik Elektro Fakultas Teknik Universitas Halu Oleo \\ Email Corespondent Author : daengbaco@gmail.com
}

\begin{abstract}
In this tool a prototype of an Arduino Uno-based Automatic Packing System will be created using Infra Red Distance Sensors. The design of this automatic packing system consists of a conveyor with a DC motor as a conveyor drive. Item detection utilizes Arduino uno technology as a microcontroller, infrared sensor and LCD. When the item is detected, the infrared sensor will take data. The data taken will be sent to Arduino uno and displayed to the LCD. The enhancements are motor drivers and I2C. All of these components can work automatically because it is controlled by Arduino Uno as a control center. Overall this system consists of the design of goods sensors, goods controllers, conveyors, and power supplies. The test phase of this tool covers, tests the sensor circuit, tests the motor driver circuit, and automatically tests the item counting process. The test results show that the design of the tool can work well in the process of selecting and calculating the number of items.
\end{abstract}

Keywords: Arduino Uno, Infrared Sensor, DC Motor, LCD, Conveyor.

Abstrak - Pada alat ini akan dibuat sebuah prototype Perancangan Sistem Pengepakan Otomatis Berbasis Arduino Uno Menggunakan Sensor Jarak Infra Red. Perancangan sistem pengepakan otomatis ini terdiri dari sebuah konveyor dengan motor DC sebagai penggerak konveyor. Pendeteksian barang memanfaatkan teknologi Arduino uno sebagai mikrokontroler, sensor infra red dan LCD. Ketika barang dideteksi maka sensor infra red akan melakukan pengambilan data. Data yang diambil akan dikirim ke Arduino uno dan ditampilkan ke LCD. Adapun perangkat tambahan berupa Driver motor dan I2C. Seluruh komponen ini dapat bekerja secara otomatis karena di kendalikan oleh arduino uno sebagai pusat pengentrollan. Secara keseluruhan sistem ini terdiri dari perancangan sensor barang, pengendali barang, konveyor, dan catu daya. Tahapan uji coba alat ini meliput, uji rangkaian sensor, uji coba rangkaian driver motor, dan uji coba proses penghitungan barang secara otomatis. Hasil pengujian menunjukan rancang bangun alat sudah dapat bekerja dengan baik dalam melakukan proses penyeleksian dan perhitungan jumlah barang.

Kata Kunci : Arduino Uno, Sensor Infra Red, Motor DC, LCD, Konveyor.

\section{PENDAHULUAN}

Permasalahan di dalam dunia industri atau perdagangan biasanya adalah bagaimana cara memproses suatu alat dengan cepat, salah satunya yakni proses penghitungan barang. Tidak mungkin atau akan menyusahkan bila, kita memerintahkan manusia menghitung barang yang jumlahnya sampai ratusan atau ribuan, bahkan jutaan .

Pada tugas akhir saya ini, saya akan membuat Perancangan sistem pengepakan Otomatis berbasis Arduino Uno Menggunakan Sensor Jarak Infra Red. Yang dimana alat ini akan otomatis menghitung barang yang lewat di depan sensor, yakni sensor jarak infra merah. Di lengkapi juga dengan sistem konveyer sebagai penggerak benda dan tombol reset untuk mengulangi proses perhitungan secara otomatis dimulai dari awal atau angka nol.

Alasan yang mendasari saya memilih Perancangan sistem pengepakan Otomatis berbasis arduino uno Menggunakan Sensor Jarak Infra Red sebagai tugas akhir saya tidak jauh berbeda dari penilitian - penilitian terdahulu, yakni membantu dan mempermudah manusia, pekerja atau buruh dalam suatu pabrik, industri maupun suatu instansi perusahaan dalam menghitung suatu benda, barang ataupun produk yang meraka hasilkan atau yang telah mereka produksi dalam jumlah yang besar dengan menggunakan waktu yang lebih efisien serta meminimalisir suatu kesalahan dalam suatu proses perhitungan bila dilakukan dengan cara manual.

\section{LANDASAN TEORI}

\subsection{Penelitian Terdahulu}

Mesin serupa pernah di buat pada sebuah karya dengan judul Rancang bangun alat pemilah dan penghitung barang dengan menggunakan laser berbasis mikrokontroler.Pada karya tersebut "Proses kerja alat adalah pertama menekan tombol ON-OFF pada rangkaian minsys ATMEGA 16 dan motor DC.Kemudian terjadi setting atau cek latar untuk membedakan warna hitam dan putih pada benda.Setelah cek latar, menaruh benda warna hitam / putih diatas konveyor yang berjalan melewati sensor pendeteksi warna dan jumlah benda. Maka akan secara otomatis sensor laser dan sensor warna dapat membedakan antara warna hitam dan putih dengan menggunakan rangkaian mikrokontroler. Bila benda hitam yang terdeteksi oleh sensor maka benda akan dipindahkan ke bagian kanan oleh lengan robot, sedangkan bila sensor mendeteksi benda berwarna putih maka akan secara otomatis dipindahkan kearah kiri."(C Hadi P dan Nurhayati, 2013, 5). Penelitian ini akan menambahkan beberapa warna yang dideteksi adalah merah, hijau, dan 
biru. Pemilahan barang / objek menggunakan servo dengan sistem ayun 2 sehingga lebih efisien dalam torque dan ruang. Peletakkan sensor warna pada sebuah tempat yang terlindung, sehingga meminimalisir gangguan cahaya dari luar sistem.Mesin penghitung barang yang dapat melakukan perhitungan sesuai dengan item warna memiliki komponen inti seperti sensor, prosessor dan juga aktuator.Sensor memiliki kemampuan untuk memilah warna sehingga dapat dijadikan acuan yang tepat untuk dihitung. Processor memiliki kemampuanuntuk mengimplementasikan semua proses yang diharapkan. Proses tersebut adalah menerjemahkan data input dari sensor berupa data ADC, melakukan proses perhitungan, membangkitkan data PWM untuk mengendalikan aktuator dan juga menampilkan data hasil perhitungan pada display. Atmega 32 memiliki fitur, jumlah port dan memori penyimpanan yang besar sehingga Atmega 32 sesuai dengan kebutuhan tersebut.

Berdasarkan uraian diatas, maka penulis mengajukan Penelitian dengan judul "Alat Pencacah/Penghitung Otomatis Berbasis Mikrokontroller Dengan Menggunakan Sensor Jarak Infra RED”. Alasan saya menggunakan sensor jarak "Infra RED” karena dari beberapa uraian penelitian terdahulu diatas, tidak ada yang menggunakan sensor jarak infra red, maka dari itu saya bertujuan untuk mencoba hal baru sebagai bentuk pengembangan dari alat penghitung otomatis.

Adapun untuk keunggulan dari judul alat yang saya ajukan sebagai tugas akhir saya, pada dasarnya semua alat penghitung otomatis baik itu berupa penghitung, buah, benda, barang, mobil, maupun bibit ikan sekalipun, memiliki prinsip kerja atau cara kerja yang tidak jauh berbeda. Namun pada alat yang saya ajukan ini saya mencoba untuk membuat alat penghitung otomatis yang lebih sederhana sehingga mudah di kembangkan dan digunakan baik untuk suatu industri, perusahaan atau instansi kecil, menengah maupun yang berskala besar.Sederhana dalam artian arsitektur atau bentuk tampilan alat ini tidak menggunakan banyak biaya, sehingga mencoba meminimalisir dalam hal pengeluaran biaya pembuatannya. Namun selain itu dalam perancangan pembuatan alat penghitung otomatis ini yang tergolong sederhana dan murah saya mencoba membuat alat ini dengan tanpa mengurangi efisiensi dan keakuratan alat ini pada saat penerapan atau pengaplikasiannya saat digunakan.

\subsection{Mikrokontoler}

Mikrokontroler adalah sebuah chip yang berfungsi sebagai pengontrol rangkaian elektronik dan

umunya dapat menyimpan program didalamnya. Mikrokontroler umumnya terdiri dari CPU (Central Processing Unit), memori, I/O tertentu dan unit pendukung seperti Analog-to-Digital Converter (ADC) yang sudah terintegrasi di dalamnya.
Arduino adalah pengendali mikro single-board yang bersifat open- source diturunkan dari Wiring platform dirancang untuk memudahkan penggunaan elektronik dalam berbagai bidang.

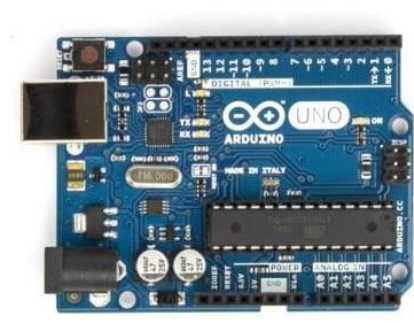

\section{Gambar 2.1 Arduino Uno}

\subsection{Sensor Jarak Infra Red (IR)}

Infra red (IR) detektor atau sensor infra merah adalah komponen elektronika yang dapat mengidentifikasi cahaya infra merah (infra red, IR).Sensor infra merah atau detektor infra merah saat ini ada yang dibuat khusus dalam satu modul dan dinamakan sebagai IR Detector Photomodules. IR Detector Photomodules merupakan sebuah chip detektor inframerah digital yang di dalamnya terdapat fotodiode dan penguat (amplifier).

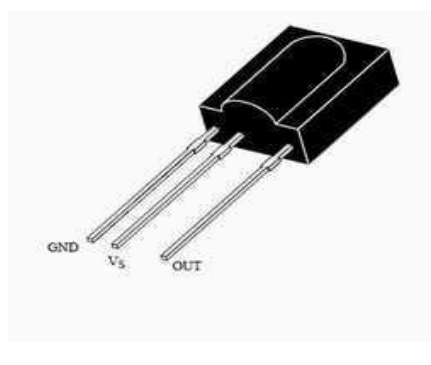

Gambar 2.2 Bentuk dan Konfigurasi Pin IR Detector Photomodules TSOP

\subsection{Arduino}




\section{$2.5 L C D 16 x 2$}

LCD kepanjangan dari Liquid Crystal Display, merupakan jenis penampil yang mepergunakan kristal cair sebagai bahan untuk menampilkan data yang berupa tulisan maupun gambar. Pengaplikasian pada kehidupan sehari - hari yang mudah dijumpai antara lain pada kalkulator, gamebot, televisi, atau pun layar komputer.LCD (Liquid Crystal Display) merupakan komponen elektronika yang digunakan untuk menampilkan suatu karakter, baik itu angka, huruf atau karakter tertentu, sehingga tampilan tersebut dapat dilihat secara visual.Pemakaian LCD sebagai tampilan banyak digunakan karena daya

\subsubsection{Pin - pin LCD 16x2 dan Keterangan}

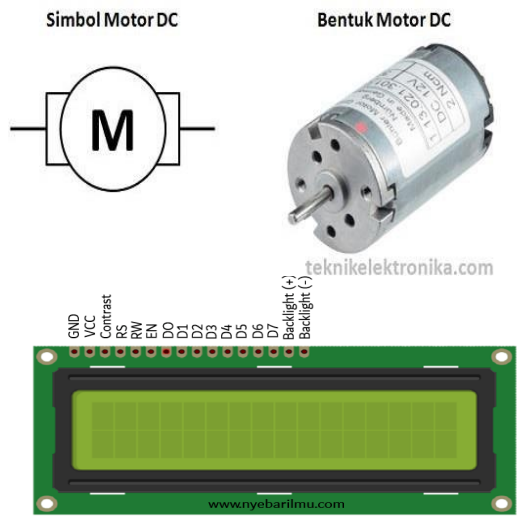

Gambar 2.8 Pin - Pin LCD 16x2
7. $\mathbf{D 0}-\mathbf{D} 7=$ Data Bus $0-7$

8. Backlight + : disambungkan ke VCC untuk menyalakan lampu latar

9. Backlight - : disambungkan ke GND untuk menyalakan lampu latar

\subsection{Motor DC}

Motor Listrik DC atau DC Motor adalah suatu perangkat yang mengubah energi listrik menjadi energi kinetik atau gerakan (motion).Motor DC ini juga dapat disebut sebagai Motor Arus Searah.Seperti namanya, DC Motor memiliki dua terminal dan memerlukan tegangan arus searah atau DC (Direct Current) untuk dapat menggerakannya.Motor Listrik DC ini biasanya digunakan pada perangkat- perangkat Elektronik dan listrik yang menggunakan sumber listrik DC seperti Vibrator Ponsel, Kipas DC dan Bor Listrik DC.Motor Listrik DC atau DC Motor ini menghasilkan sejumlah putaran per menit atau biasanya dikenal dengan istilah RPM (Revolutions per minute) dan dapat dibuat berputar searah jarum jam maupun berlawanan arah jarum jam apabila polaritas listrik yang diberikan pada Motor DC tersebut dibalikan. Motor Listrik DC tersedia dalam berbagai ukuran rpm dan bentuk. Kebanyakan Motor Listrik DC memberikan kecepatan rotasi sekitar $3000 \mathrm{rpm}$ hingga $8000 \mathrm{rpm}$ dengan tegangan operasional dari 1,5V hingga $24 \mathrm{~V}$.

Gambar2.9 simbol dan bentuk motor DC

Keterangan :

1. GND : catu daya $0 \mathrm{Vdc}$

2. VCC : catu daya positif

3. Constrate : untuk kontras tulisan pada LCD

4. RS atau Register Select :

- High : untuk mengirim data

- Low : untuk mengirim instruksi

5. $R / W$ atau Read/Write

- High : mengirim data

- Low : mengirim instruksi

- Disambungkan dengan LOW untuk pengiriman data ke layar

6. E (enable) : untuk mengontrol ke LCD ketika bernilai LOW, LCD tidak dapat diakses 


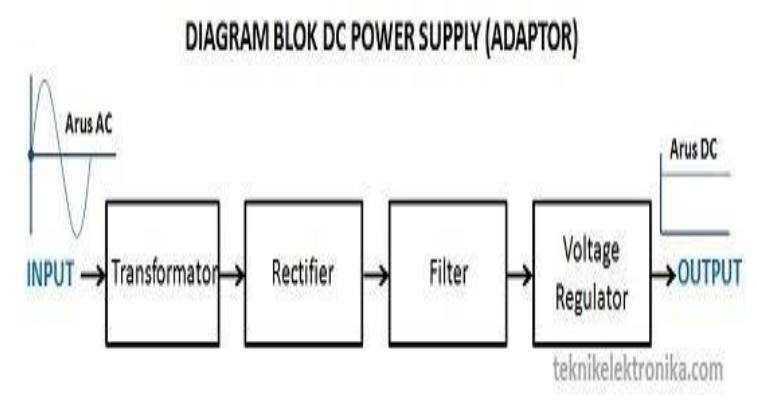

\subsection{Driver Motor}

Driver Motor adalah modul untuk motor yang memungkinkan Anda mengontrol kecepatan kerja dan arah dua motor secara bersamaan. Driver Motor ini dirancang dan dikembangkan berdasarkan IC L293D.L293D adalah IC Driver Motor dengan banyaknya Pin sebanyak 16.Ini dirancang untuk memberikan arus penggerak bidirectional pada tegangan dari $5 \mathrm{~V}$ sampai $36 \mathrm{~V}$.

Gambar. 2.11 Konstruksi pin driver motor DC IC 1293D

Adapun Fungsi dari Pin Driver Motor DC IC L293Dadalah :

- $\quad$ Pin EN (Enable, EN1.2, EN3.4) berfungsi untuk mengijinkan driver menerima perintah untuk menggerakan motor DC.

- $\quad$ Pin In (Input, 1A, 2A, 3A, 4A) adalah pin input sinyal kendali motor DC

- $\quad$ Pin Out (Output, 1Y, 2Y, 3Y, 4Y) adalah jalur output masing-masing driver yang dihubungkan ke motor DC

- Pin VCC (VCC1, VCC2) adalah jalur input tegangan sumber driver motor DC, dimana VCC1 adalah jalur input sumber tegangan rangkaian kontrol dirver dan VCC2 adalah jalur input sumber tegangan untuk motor DC yang dikendalikan.

- $\quad$ Pin GND (Ground) adalah jalu yang harus dihubungkan ke ground, pin GND ini ada 4 buah yang berdekatan dan dapat dihubungkan ke sebuah pendingin kecil.

\section{$2.812 C$}

Inter Integrated Circuit atau sering disebut $\mathrm{I}^{2} \mathrm{C}$ adalah standar komunikasi serial dua arah menggunakan dua saluran yang didisain khusus untuk mengirim maupun menerima data.

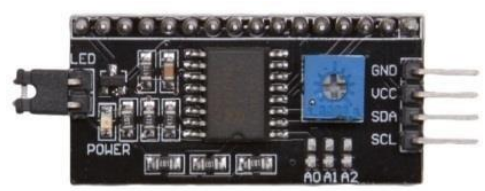

\section{Gambar 2.12 bentuk fisik I2C}

\subsection{Catu Daya}

Catu Daya atau sering disebut dengan Power Supply adalah sebuah piranti yang berguna sebagai sumber listrik untuk piranti lain. Pada dasarnya Catu Daya bukanlah sebuah alat yang menghasilkan energi listrik saja, namun ada beberapa Catu Daya yang menghasilkan energi mekanik, dan energi yang lain.

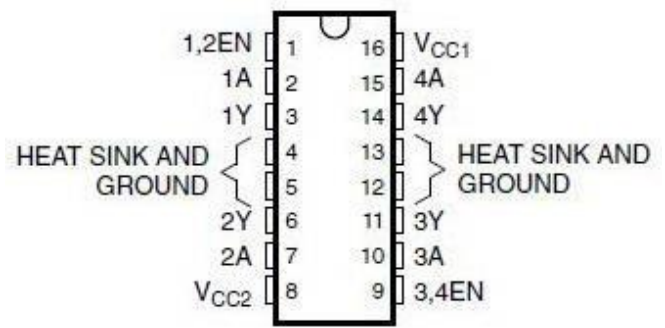

Daya untuk menjalankan peralatan elektronik dapat diperoleh dari berbagai sumber.

\section{Gambar. 2.13 Blok Diagram Blok DC Power Supply \\ III. METODE PENELITIAN}

\subsection{Tahapan Penelitian}

Sebelum melakukan sebuah penelitian perlu dibuat sebuah susunan tahapan-tahapan penelitian. Adapun susunan atau tahapan penelitian tersebut mempunyai fungsi untuk menetapkan langkah-langkah yang tepat agar penelitian dapat berjalan secara terstruktur dan dapat mengurangi resiko yang ditimbulkan pada saat penelitian berlangsung, misalnya kesalahan dalam teori penerapan, penyusunan anggaran alat dan bahan yang diperlukan pada penelitian tersebut. Berikuttahapan- tahapan penelitian yang dilakukan dalam penelitian ini diperlihatkan pada gambar 3.1 


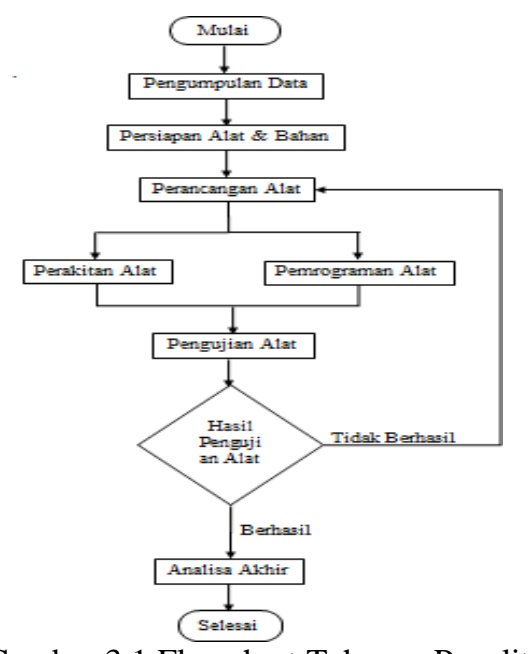

Gambar 3.1 Flowchart Tahapan Penelitian

\subsection{Perancanagan Sistem Blok Diagarm}

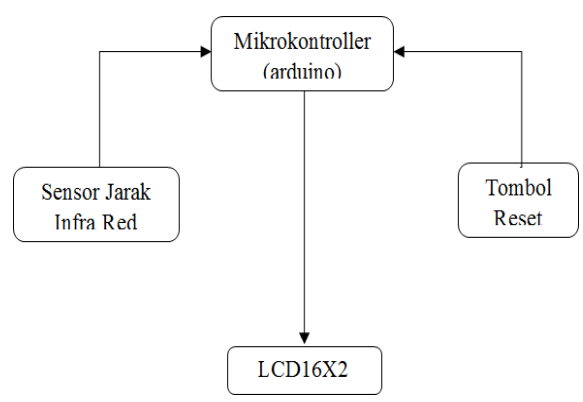

Gambar 3.2 Blok Diagram Alat

Cara kerja dari prototype alat pengepakan otomatis ini adalah alat ini akan menghitung secara otomatis setiap benda yang melintas atau melewati sensor jarak infra red, yang dimana sensor jarak tersebut diletakkan disalah satu sudut konveyor. Konveyor disini berfungsi sebagai alat penggerak benda yang secara otomatis akan membawa benda menuju sensor jarak, agar benda tersebut dapat terdeteksi atau terbaca oleh sensor jarak infra red. Alat ini mengguakan sumber tegangan $12 \mathrm{v}$ dari sebuah adaptor untuk mengaktifkan proses kerja dari sistem mikrokontroller, dan disisni saya menggunakan Arduino sebagai sistem mikrokontroller pada perancangan system pengepakan otomatis menggunakan sensor jarak infra red berbasis Arduino uno yang akan saya buat.

\subsection{Alur Prinsip Kerja Alat}

Perancangan sistem pengepakan otomatis berbasis arduino uno menggunakan sensor jarak infra red ini memiliki alur prinsip kerja yang tergolong sederhana atau tidak tergolong rumit. Alat ini menggabungkan beberapa komponen utama seperti sensor jarak infra red, potensio 10k, LCD 16x2 dan lain-lain. Berikut adalah contoh gambar sketsa alur prinsip kerja Alat penghitung/pencacah otomatis menggunakan sensor jarak infra red berbasis mikro kontroller.

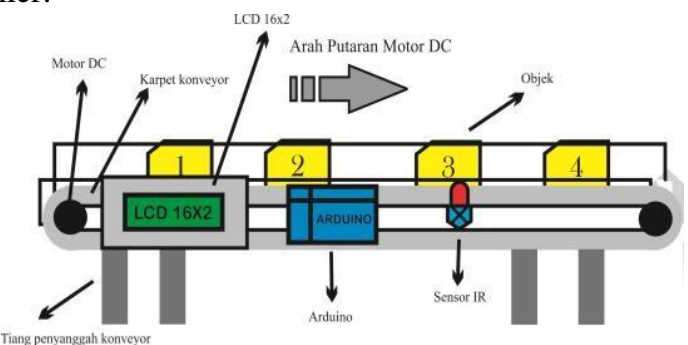

Gambar 3.3 SketsaAlur Prinsip Kerja Alat 


\section{HASIL DAN PEMBAHASAN}

\subsection{Perancangan Sistem}

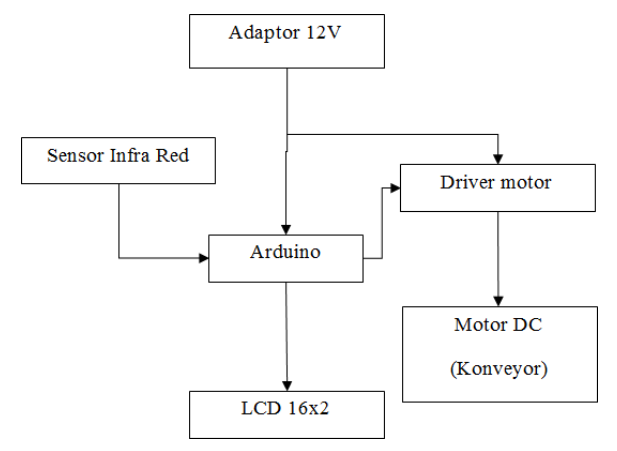

Gambar 4.1 Blok Diagram Sistem

Penjelasan mengenai proses kerja dari gambar blok diagram diatas tentang perancangan sistem pengepakan otomatis berbasis arduino uno menggunakan sensor jarak infra red adalah sebagai berikut. Prinsip kerja dari prototipe alat perancangan sistem pengepakan otomatis ini adalah alat ini akan menghitung secara otomatis setiap benda yang melintas atau melewati sensor jarak infra red, yang dimana sensor jarak tersebut diletakkan disalah satu sudut konveyor. Konveyor disini berfungsi sebagai alat penggerak benda yang secara otomatis akan membawa benda menuju sensor jarak, agar benda tersebut dapat terdeteksi atau terbaca oleh sensor jarak infra red. Alat ini mengguakan sumber tegangan $12 \mathrm{v}$ dari sebuah adaptor untuk mengaktifkan proses kerja dari sistem mikrokontroller, dan disisni saya menggunakan Arduino sebagai sistem mikrokontroller pada alat penghitung otomatis menggunakan sensor jarak infra red berbasis Arduino uno yang akan saya buat.

\subsection{Perancangan alat}

Pada perancangan alat sistem pengepakan otomatis ini, dilakukan penggabungan dari beberapa komponen utama seperti Aduino uno sebagai pusat pengontrollan, sensor jarak sebagai pembaca atau penghitung barang/benda, tombol reset untuk merestart penghitungan kembali ke awal, Driver motor untuk mengatur proses putaran motor DC pada konveyor dan LCD 16x2 sebagai tampilan dari proses penghitungan barang/benda. Dan untuk sumber tegangan menggunakan adaptor $12 \mathrm{v}$.

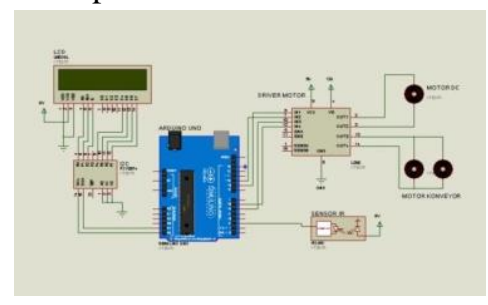

Gambar 4.2 Skema Perancangan Alat.

\subsection{Flowchart Sofware}

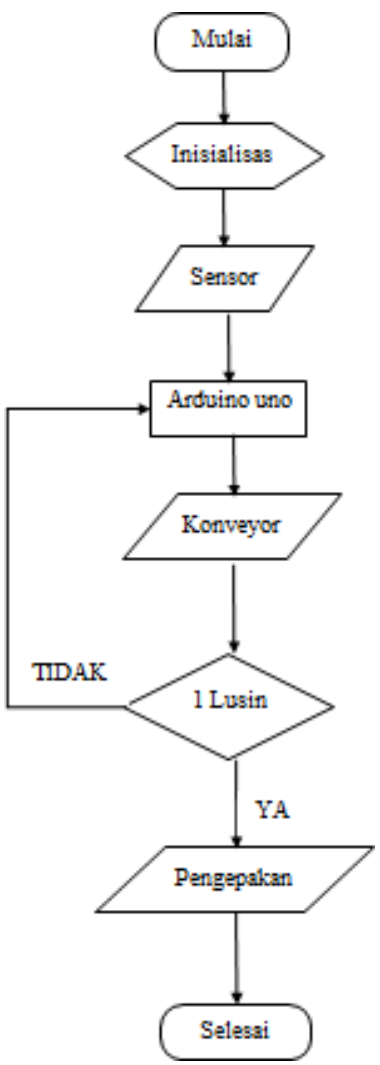

Gambar 4.3 Flowchart Alur Kerja Program Arduino

\subsection{Pengujian Sistem}

\subsubsection{Pengujian Kesensifitas Sensor Jarak Infra Red}

Sensor jarak Infra Red memiliki kesensitifan jarak yang tidak terlalu besar. Untuk mengatur kepekaan sensor bisa memutar potensio VR1 pada rangkain sensor. Untuk prototype perancangan sistem pengepakan otomatis berbasis arduino uno menggunakan sensor jarak infra red yang saya rancang, sensor jarak infra red yang saya gunakan memiliki kesensitifan dalam pembacaan data untuk jarak lingkup yang kecil. Dimana jarak maksimal pembacaan sensor infra red yang saya gunakan sebesar $15 \mathrm{~cm}$.

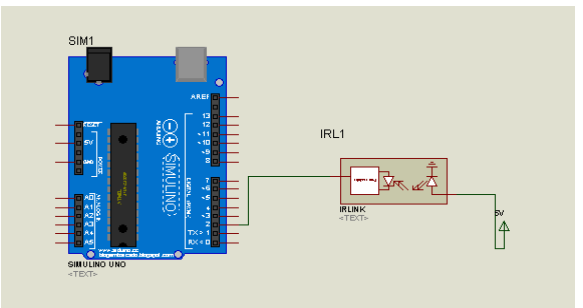


Gambar 4.4 Rangkaian Sensor Jarak Infra Red pada Arduino uno 4.4.2 Komunikasi serial

Sebelum memberikan program perlu diatur konfigurasi pin kedua modul yaitu dengan menghubungkan pin 2 Arduino uno ke pin OUT sensor jarak infra red, pin VCC arduino uno ke pin VCC sensor jarak infra red, begitu pula pin GND Arduino uno ke pin GND sensor jarak infra red.

Setelah itu kita upload program tersebut ke board arduino dan kemudian lihat LCD untuk memastikan apakah perintah yang telah diberikan berhasil menghubungkan kedua board tersebut, jika pengujian berhasil maka pada LCD akan tampil seperti pada gambar dibawah ini.

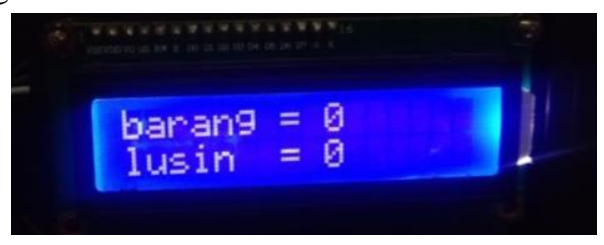

Gambar 4.6 Tampilan awal LCD sebelum Penghitungan

Setelah semua rangkaian sudah di pastikan terhubung dengan baik, maka proses penghitungan benda sudah bisa untuk dimulai. Apabila benda sudah terdeteksi oleh sensor infra red, maka akan terjadi proses penghitungan dan tampilan pada LCD 16x2 akan beubah, seperti gambar di bawah ini.

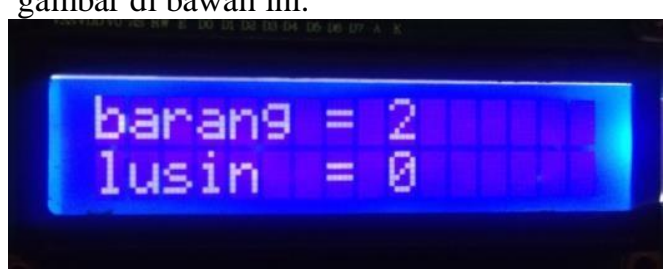

Gambar 4.7 Tampilan LCD pada saat penghitungan

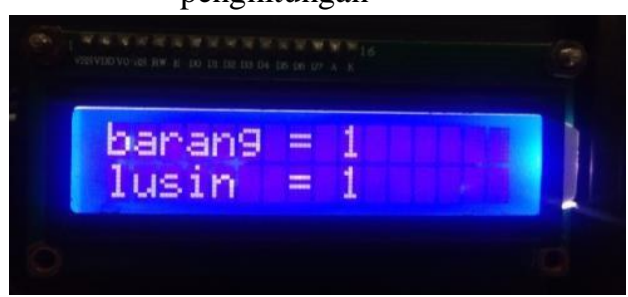

Gambar 4.8 Tampilan LCD saat penghitungan telah mencapai 1 Lusin

Setelah penghitungan telah mencapai satu lusin maka konveyor akan berhenti sejenak untuk melakukan proses pengepakkan pada benda yang telah dihitung secara otomatis tadi oleh sensor jarak infra red. Kemudian arduino uno akan merestart penghitungan ke awal kembali untuk memulai proses penghitungan menuju ke lusin selanjutnya

\subsection{Analisa Data}

4.5.1 Analisa Jarak Benda Terhadap Pembacaan Sensor Jarak Infra Red

Hasil dari analisa jarak benda terhadap pembacaan sensor jarak infra red mengenai kesensitifan sensor dan kemungkinan terjadinya error saat proses pembacaan atau penghitungan benda akan di buat dalam bentuk tabel. Berikut tabel analisa jarak benda terhadap pembacaan sensor jarak infra red.

Tabel. 4.1 Tabel Analisa Jarak Benda Terhadap Pembacaan Sensor Jarak Infra Red.

\begin{tabular}{|c|c|c|}
\hline No. & $\begin{array}{c}\text { Jarak } \\
\text { Benda }\end{array}$ & $\begin{array}{c}\text { Kesensitifan } \\
\text { Sensor } \\
(\text { Waktu m/s })\end{array}$ \\
\hline 1. & $3 \mathrm{~cm}$ & $0,74 \mathrm{~m} / \mathrm{s}$ \\
\hline 2. & $5 \mathrm{~cm}$ & $0,91 \mathrm{~m} / \mathrm{s}$ \\
\hline 3. & $7 \mathrm{~cm}$ & $0,95 \mathrm{~m} / \mathrm{s}$ \\
\hline 4. & $9 \mathrm{~cm}$ & $1,51 \mathrm{~m} / \mathrm{s}$ \\
\hline 5, & $11 \mathrm{~cm}$ & $1,56 \mathrm{~m} / \mathrm{s}$ \\
\hline 6. & $! 3 \mathrm{~cm}$ & $1,68 \mathrm{~cm}$ \\
\hline 7. & $15 \mathrm{~cm}$ & $1,70 \mathrm{~cm}$ \\
\hline
\end{tabular}

\section{Jarak \& Waktu $(\mathrm{m} / \mathrm{s})$}

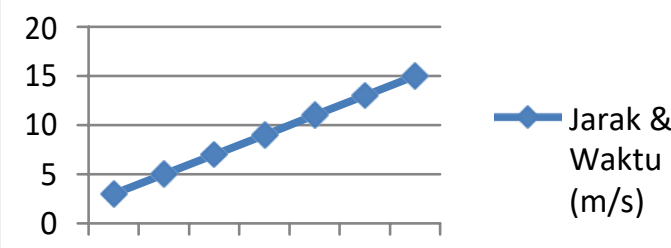

Gambar 4.10 Grafik Analisa Jarak Benda Terhadap Pembacaan Sensor Jarak Infra Red.

\subsubsection{Analisa Time Chart}

Untuk melakukan analisa pada perancangan sistem pengepakan otomatis berbasis arduino uno menggunakan sensor jarak infra red ini dapat dilakukan dengan cara membuat time chart, sebagai berikut : 


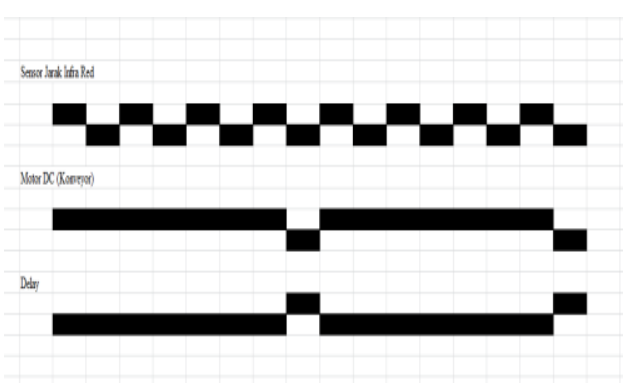

Gambar 4.11 Analisis Time Chart

Berdasarkan dari gambar time chart diatas dapat dibaca atau disumpulkan bahwa, proses pengepakan dimulai dari proses penghitungan barang atau benda . proses penghitungan benda dibatasi sampai pada hitungan satu lusin, yang dimana bila hitungan benda telah mencapai satu lusin, maka konveyor akan berhenti sejenak dan proses delay akan terjadi. Pada prototipe perancangan sistem pengepakan otomatis berbasis arduino uno menggunakan sensor jarak infra red ini, saya menjadikan hitungan benda ke empat sebagai akhir hitungan, atau dengan kata lain, bila total benda telah mencapai empat buah benda, maka hitungan telah sampai pada lusin pertama. Dikarenakan untuk lebih mengefisienkan waktu pada saat pengujian alat berlangsung nantinya.

Setelah proses penghitungan barang lusin pertama selesai, maka konveyor akan berhenti, sehingga proses penghitungan barang yang secara otomatis juga ikut brthenti. Disaat inilah proses delay bekerja untuk beberapa saat, dimana sesuai dengan waktu delay yang telah ditentukan. Setelah waktu delay berakhir maka konveyor akan kembali bekerja dan proses penghitungan benda dimulai kembali. Penghitungan benda kembali dimulai pada bilangan awal penghitungan benda untuk menuju penghitungan benda ke lusin berikutnya.

\section{KESIMPULAN DAN SARAN}

\subsection{Kesimpulan}

Dari sistem perancangan alat pengepakan otomatis berbasis Arduino uno menggunakan sensor jarak infra red ini, dapat ditarik beberapa kesimpulan, sebagai berikut :

1. Untuk merancang rangkaian alat pengepakan otomatis ini akan dilakukan penggabungan dari beberapa komponen utama seperti Arduino Uno sebagai mikrokontroller, Sensor Jarak Infra Red, sebuah Potensio 10k, LCD $16 \times 2$, dan sebuah system penggerak berupa Konveyor.
2. Untuk menganalisis atat penghitung otomatis ini, maka dilakukan analisa jarak benda terhadap pembacaan sensor jarak infra red, serta analisa pada sensor jarak infra red, motor DC yang dimana berfungsi sebgai konveyor dan proses delay pada target akhir penghitungan benda yang dibuat dalam bentuk time chart

\subsection{Saran}

Untuk penggunaan catu daya pilihlah adaptor yang mempunyai tegangan dan arus yang cukup memadai sesuai jumlah beban rangkaian yang buat agar kinerja sistem maksimal.

Pengembangan selanjutnya diharapkan dapat menyempurnakan penelitian ini sehingga dapat dioperasikan jauh lebih baik lagi dan mudah untuk diterapkan pada masyarakat

\section{DAFTAR PUSTAKA}

[1] Mokh. Sholihul Hadi, "Mengenal Mikrokontroler ATMega 16," Ilmu Komputer.com, 2003.

[2] F. Alfiandi, "Rancang Bangun Alat Deteksi Benda Bergerak menggunakan Sensor Ultrasonik," Jurusan Teknik Fisika FTI ITS, 2010.

[3] Handayani and Dwi, "Sistem Otomatisasi Penghitung Jumlah Barang berdasarkan Ukuran Tinggi berbasis Mikrokontroller AT89S51,"Universitas Gunadarma, 2012.

[4] Sumanto, Mesin Arus Searah. Andi Offset, 1994.

[5] Zuhal, Dasar Teknik Tenaga Listrik dan Elektronika Daya. Gramedia, 1988.

[6] Andrianto Heri, Pemrograman Mikrokontroller AVR Atmega 16. 2008.

[7] Budiharo and Widodo, Perancangan Sistem dan Aplikasi Mikrokontroler. Jakarta: Elex Media Komputindo, 2005.

[8] Boylestad, Robert dan Nashelsky, and Louis, "Electronic Devices and Circuit Theory," Prentice Hall International. New Jersey, 1992

[9] Dyah Nur'ainingsih and Irwan Tri Handoyo, "Sistem Kendali Conveyor Otomatis Berbasis Mikrokontroller AT89S51," Jurusan Teknik Elektro, Fakultas Teknologi Industri, Universitas Gunadanna.

[10] A. Miftahudin, "Simulator Penghitung Jumlah Orang pada Pintu Masuk dan Keluar Gedung.," Fakultas Teknik. Universitas Negeri Semarang. Semarang, Indonesia, 2007.

[11] I. G. A. P. Raka Agung and I. M. I. Susanto, "Rancangbangun Prototipe Penghitung Jumlah Orang dalam Ruangan Terpadu berbasis Mikrokontroler ATMega328P.," J. Teknol. Elektro, vol. 11(1), pp. 41-49, 2012.

[12] Sinukun R. S., H. S., and P. M.H., "Identifikasi Jumlah Citra Nener menggunakan Metode Blob. Prosiding," in Seminar Nasional Aplikasi Sains \& Teknologi (SNAST), 2014, pp. 99-104.

[13] Seniatussa'adah, "Otomatisasi Size Grading Benih Ikan," Fakultas Perikanan dan Ilmu Kelautan. Institut Pertanian Bogor, Indonesia, 2008. 